\title{
Comment to "High and highly anisotropic electrical conductivity of the asthenosphere due to hydrogen diffusion in olivine" by Dai and Karato [Earth Planet. Sci. Lett. 408 (2014) 79-86]
}

\author{
Emmanuel Gardés $^{\mathrm{a}, *}$, Fabrice Gaillard ${ }^{\mathrm{b}, \mathrm{c}, \mathrm{d}}$, Pascal Tarits ${ }^{\mathrm{e}}$ \\ a CEA-CNRS-ENSICAEN-Université de Caen Basse Normandie, CIMAP, UMR 6252, BP 5133, 14070 Caen, France \\ b Université d'Orléans, ISTO, UMR 7327, 45071 Orléans, France \\ c CNRS/INSU, ISTO, UMR 7327, 45071 Orléans, France \\ d BRGM, ISTO, UMR 7327, BP 36009, 45060 Orléans, France \\ e Université de Bretagne Occidentale-CNRS, IUEM, UMR 6538, 29280 Plouzané, France
}

\section{A R T I C L E I N F O}

\section{Article history:}

Received 24 December 2014

Accepted 2 June 2015

Editor: J. Brodholt

\section{Keywords:}

mantle electrical conductivity

hydrous olivine

water in nominally anhydrous minerals

\begin{abstract}
A B S T R A C T
Dai and Karato (2014a) reported new electrical conductivity measurements on oriented single crystals of hydrous olivine showing a higher increase in conductivity and conductivity anisotropy at high temperature than previously reported. After recalling that the highest conductivities of the upper mantle (e.g. $>0.1 \mathrm{~S} / \mathrm{m}$ ) cannot reasonably be explained by previous hydrous olivine conductivity data, they concluded from their new measurements that olivine hydration can actually account for the electrical anomalies of the upper mantle. However, we analyze the data of Dai and Karato (2014a) and demonstrate that they are not higher but lower than most previous measurements and models, including those of the same authors, even when extrapolated at upper mantle temperatures. This new study therefore does not extend but restricts the magnitude of olivine conductivity enhancement by water. We show that the high temperature conduction regime reported by Dai and Karato (2014a) cannot result from the diffusion of vacancy-hydrogen complexes as proposed by the authors, but is compatible with the diffusion of interstitial protons. We show that the high conductivity anisotropy observed in their olivine samples with high water concentration $(\sim 1000$ wt.ppm) must be drastically reduced at mantle-relevant water concentrations $(<\sim 100$ wt.ppm) since dry olivine is weakly anisotropic. We conclude from all of the existing models that olivine with mantle-relevant water concentrations is unlikely to produce significant conductivity anisotropy in deformed mantle and is unable to produce the highest conductivities of the upper mantle, which therefore likely result from partial melting.
\end{abstract}

(c) 2015 Elsevier B.V. All rights reserved.

\section{Foreword on samples water concentration}

Dai and Karato (2014a) analyzed the hydrogen content in their olivine samples using unpolarized Fourier transform infrared spectroscopy (FTIR) and the calibration of Paterson (1982) to report $\mathrm{H}_{2} \mathrm{O}$ concentrations. Dai and Karato (2014a) recalled that this calibration is known to underestimate by a factor of $\sim 3$ actual $\mathrm{H}_{2} \mathrm{O}$ concentrations (referred to as 'SIMS calibration' in their article). When conversion is required, we will here use a factor of 2.22 which is more consistent with the latest calibration of Withers et al. (2012), even though there is no simple conversion (Supplemen-

DOI of original article: http://dx.doi.org/10.1016/j.epsl.2014.10.003.

DOI of reply to comment: http://dx.doi.org/10.1016/j.epsl.2015.06.042.

* Corresponding author.

E-mail address: gardes@ganil.fr (E. Gardés). tary Information). Therefore, we consider that the 460 wt.ppm Dai and Karato (2014a) reported for their samples according to the calibration of Paterson (1982) correspond to 1020 wt.ppm instead of 1380 wt.ppm. Unless otherwise specified, water concentrations reported here are consistent with actual concentrations.

\section{Consistency of the data}

Dai and Karato (2014a) stated that their new conductivity measurements on oriented single crystals up to $1100^{\circ} \mathrm{C}$ agree well with previous studies at low temperature and significantly deviate at high temperature where the temperature dependence of conductivity increase strongly. However, the isotropic average of the conductivity measurements of Dai and Karato (2014a) is lower than the previous measurements of their group on polycrystalline olivine at identical conditions (4 GPa, Ni/NiO buffer, Paterson calibration) (Fig. 1a; Wang et al., 2006; Dai and Karato, 2014b, 2014c). 


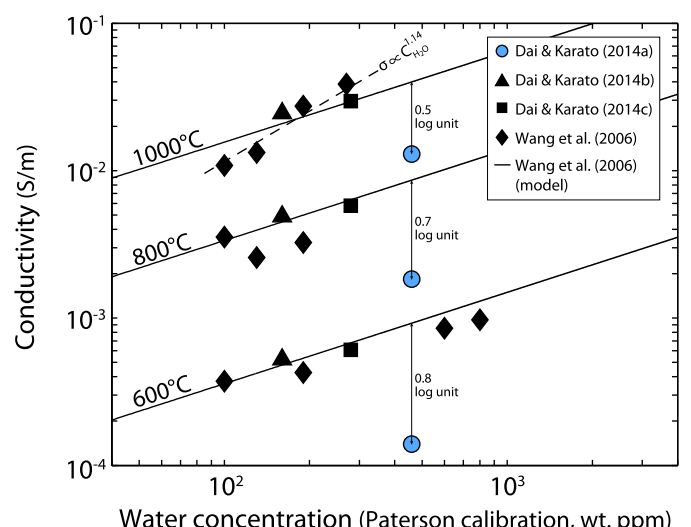

c
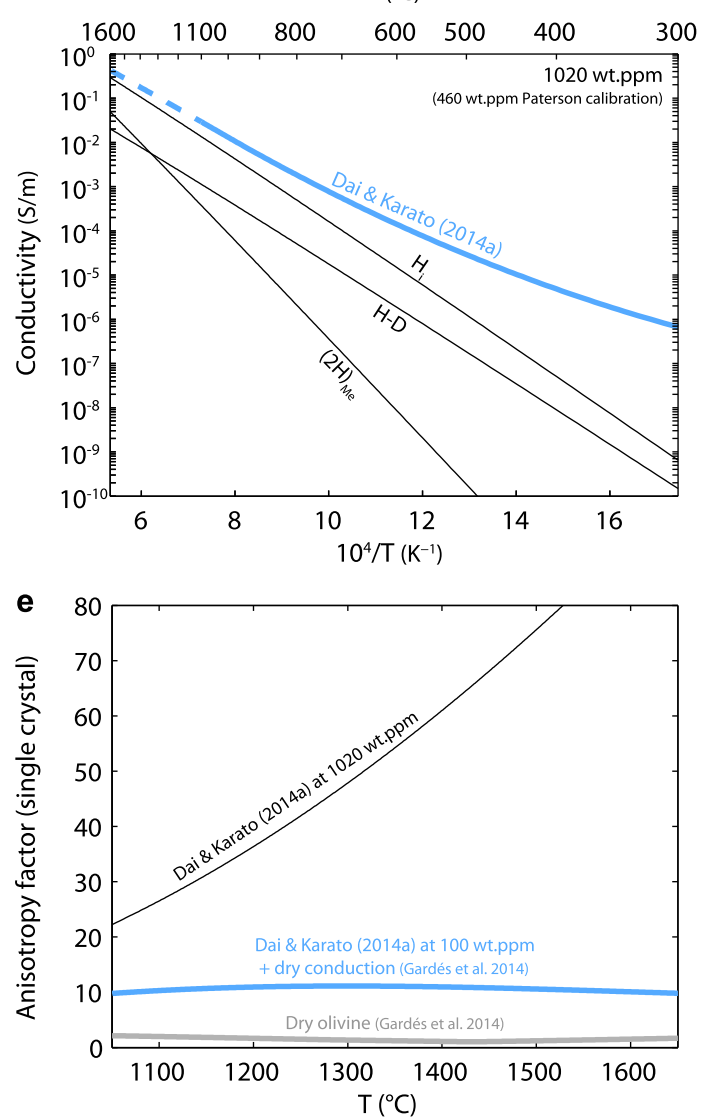

b
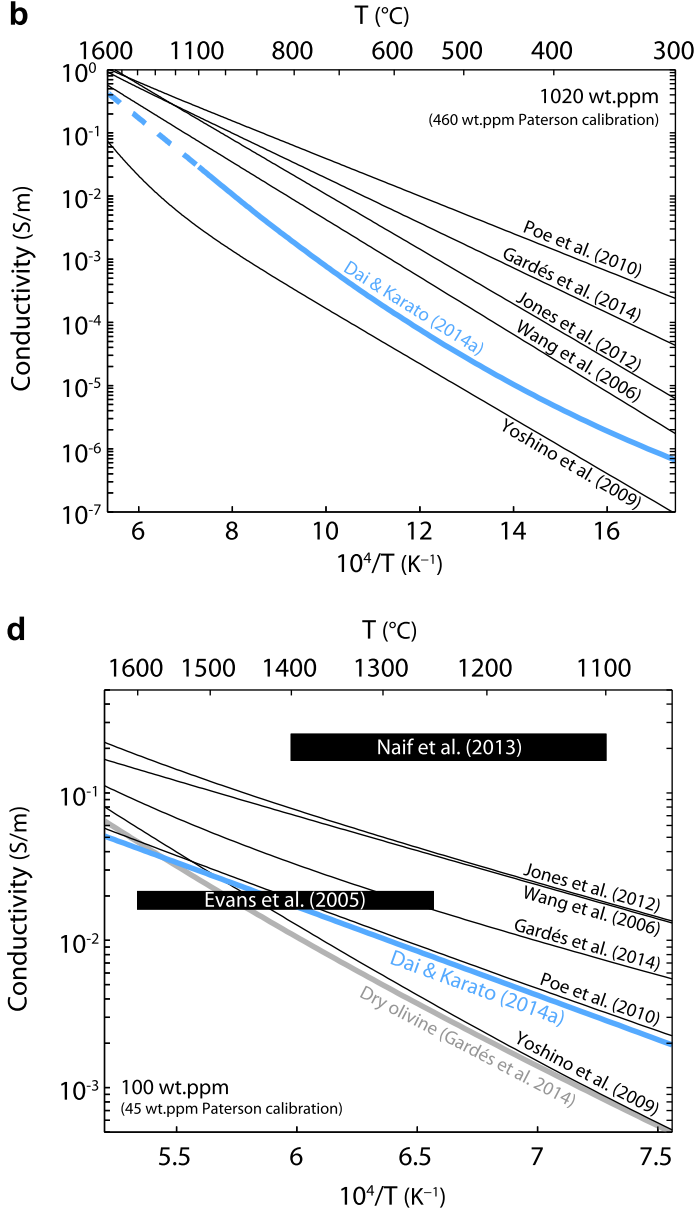

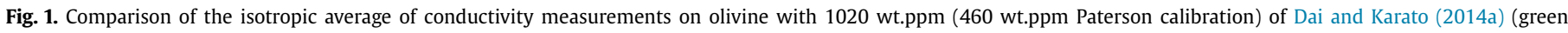

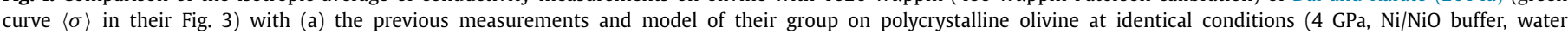

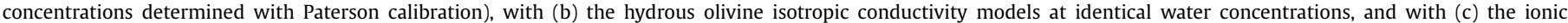

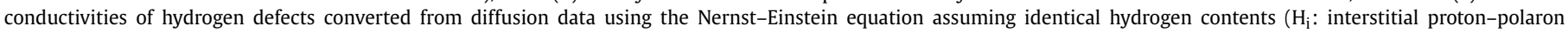

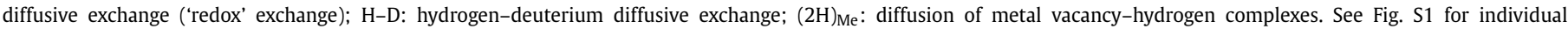

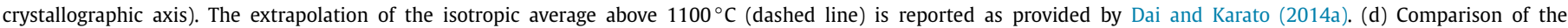

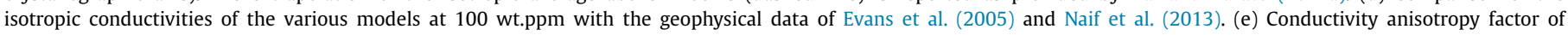

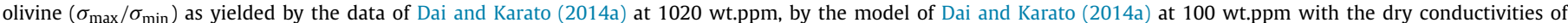
Gardés et al. (2014) added, and by the dry conductivities of Gardés et al. (2014). See Supplementary Information for details on data selection and calculations.

While these previous measurements form trends relatively consistent with the model of Wang et al. (2006) as a function of water concentration at given temperature, the new data of Dai and Karato (2014a) at 460 wt.ppm (Paterson calibration) are off trend by -0.5 to $-0.8 \log$ unit over $600-1000^{\circ} \mathrm{C}$ (Fig. 1a). This internal inconsistency is not mentioned by Dai and Karato (2014a).

The isotropic average of the conductivity measurements of Dai and Karato (2014a) is about 0.5 to $2.5 \log$ unit lower than the models of Wang et al. (2006), Poe et al. (2010), Jones et al. (2012) and Gardés et al. (2014) at equivalent concentrations over the experimental temperature range $\left(300-1100^{\circ} \mathrm{C}\right)$, and remains lower when extrapolated at higher temperatures (Fig. 1b). Only the model of Yoshino et al. (2009) yields lower conductivities. In Fig. 1a of Dai and Karato (2014a), the data representing the model of Wang et al. (2006) and Poe et al. (2010) are not representative of the water concentration of the samples of Dai and Karato (2014a) 
but of concentrations being $\sim 10$ and $\sim 3$ times lower, respectively (Supplementary Information).

Thus, the data of Dai and Karato (2014a) are actually among the lowest hydrous olivine conductivities of literature, being intermediate between the model of Yoshino et al. (2009) providing the lowest conductivities and the model of Gardés et al. (2014) reproducing the rest of the database.

\section{Conduction mechanisms}

An important point of the measurements of Dai and Karato (2014a) is that they reveal a change in conduction mechanisms since the activation energy increases at high temperature, contributing to the development of conductivity anisotropy with [100] being the most conductive axis. Dai and Karato (2014a) proposed that conduction is controlled by the diffusion of 'free' (interstitial) proton $\left(\mathrm{H}_{\mathrm{i}}\right)$ at low temperature and by the diffusion of protons associated to metal vacancies $\left((2 \mathrm{H})_{\mathrm{Me}}\right)$ at high temperature.

Dai and Karato (2014a) stated that their high temperature conductivities are compatible with the hydrogen-deuterium exchange rates reported by DuFrane and Tyburczy (2012). However, the conversion of the $\mathrm{H}-\mathrm{D}$ diffusivities using the Nernst-Einstein equation at 1020 wt.ppm (i.e. 460 wt.ppm Paterson calibration) yields conductivities being $\sim 1-2 \log$ unit lower (Figs. 1c and S1). The conversion of the data of DuFrane and Tyburczy (2012) reported in Fig. 1b of Dai and Karato (2014a) are not representative of the water concentrations in their samples, but of concentrations being $>10$ times higher (Supplementary Information).

The fastest hydrogen diffusion in olivine was observed during the initial steps of hydration experiments (Kohlstedt and Mackwell, 1998; Demouchy and Mackwell, 2006). This fast incorporation was assumed to occur via the interdiffusive exchange of interstitial proton $\left(\mathrm{H}_{\mathrm{i}}\right)$ and polaron ('redox exchange'), and to be rate-controlled by the slower proton diffusion. A second much slower mechanism of hydration was observed, where hydrogen was assumed to be associated to Me-vacancies $\left((2 \mathrm{H})_{\mathrm{Me}}\right)$ and to be rate-controlled by the slower vacancy diffusion.

The high temperature conduction regime of Dai and Karato (2014a) is not compatible with $(2 \mathrm{H})_{\mathrm{Me}}$ diffusion. It has a much lower activation energy and an anisotropy orientation opposite to $(2 \mathrm{H})_{\text {Me }}$ diffusion (87-140 vs. 204-258 kJ/mol; $\sim 1.5 \log$ unit faster along [100] than [001] vs. faster $\sim 1.5 \log$ unit faster along [001] than [100] and [010]). When converted using the Nernst-Einstein equation, the diffusivities of $(2 \mathrm{H})_{\text {Me }}$ yield much lower conductivities than measured by Dai and Karato (2014a) (Figs. 1c and S1).

We show in Figs. 1c and S1 that the high temperature conductivities of Dai and Karato (2014a) are remarkably well reproduced by $\mathrm{H}_{\mathrm{i}}$ diffusion, in term of magnitude, activation energy and anisotropy. Their low temperature conductivities, though much lower in magnitude, have a low activation energy and low anisotropy similarly to previous studies. In particular, Wang et al. (2006) and Dai and Karato (2014b; 2014c) reported low and constant activation energies $(\sim 80-90 \mathrm{~kJ} / \mathrm{mol})$ up to almost the same temperature as Dai and Karato (2014a) (1000 vs. $\left.1100^{\circ} \mathrm{C}\right)$.

Therefore, in contrast to the interpretation of Dai and Karato (2014a), their high conduction regime appears to be controlled by interstitial diffusion and their low temperature regime appears to be controlled by the same low activation energy and low anisotropy mechanism as in previous measurements. It is unclear why the latter regime was less effective in the measurements of Dai and Karato (2014a) (see Supplementary Information for further discussion). Their study however evidences that conduction by $\mathrm{H}_{\mathrm{i}}$ diffusion can be effective in hydrous olivine and suggests that this mechanism could be added to previous conductivity models. Doing so for the model of Gardés et al. (2014) enhances anisotropy at high temperature but to a much smaller extent than reported by Dai and Karato (2014a), and leaves their isotropic conductivity virtually unchanged (Fig. S2; Supplementary Information).

The exact relevance of the various measurements and models for actual mantle conditions remains to be determined. Gardés et al. (2014) have shown that their model reproduces fairly well the conductivities of a lithospheric setting where temperature and olivine water concentration are well constrained (Jones et al., 2012), whereas the model of Dai and Karato (2014a) and Yoshino et al. (2009) yield significantly lower conductivities (Supplementary Information). Fortunately, the variability of hydrous olivine conductivity data at low temperature attenuates at high temperature where the models converge (Fig. 1d), therefore unambiguous conclusions can reasonably be drawn for asthenospheric olivines.

\section{Implications for the upper mantle}

Dai and Karato (2014a) recalled that the typical mantle water concentration is $\sim 100$ wt.ppm (50-200 wt.ppm). Water concentration in olivine may differ because of partitioning between mantle minerals. Petrological surveys indicate that water concentration of olivine in equilibrium within peridotite is roughly the same as bulk peridotite at $400 \mathrm{~km}$ depth but is $\sim 5$ times lower at $130 \mathrm{~km}$ depth (Ardia et al., 2012), implying typical mantle-olivine water concentration of $\sim 50-200$ and $\sim 10-40$ wt.ppm at respective depths. Peridotite-saturated $\mathrm{H}_{2} \mathrm{O}$ storage capacity of olivine, that is maximum olivine water concentration before the onset of hydrous melting, is $\sim 500$ wt.ppm at $400 \mathrm{~km}$ and 90 wt.ppm at $130 \mathrm{~km}$ depth along a ridge adiabat (Ardia et al., 2012). 100 wt.ppm is therefore a conservative upper bound for mantle-olivine water concentration at shallow depths beneath young lithospheres.

As Dai and Karato (2014a) only performed measurements at 1020 wt.ppm (460 wt.ppm Paterson), they converted their conductivities to lower concentrations assuming $\sigma \propto C_{\mathrm{H}_{2} \mathrm{O}}^{r}$ and $r$ values ranging from 0.6 to $1, r=1$ being their preferred case at high temperature (there is indeed no evidence for $r<1$ at high temperature; Fig. 1a; Supplementary Information). Dai and Karato (2014a) concluded that hydrous olivine can account for high asthenosphere conductivities, but they focused their discussion on 100 wt.ppm according to Paterson calibration. This concentration actually corresponds to $\sim 220$ wt.ppm, which is well above typical mantle-olivine concentrations (and above the concentration at which hydrous melting occurs at shallow depths). At 100 wt.ppm (45 wt.ppm Paterson calibration), the calculations of Dai and Karato (2014a) yields conductivities below the range of asthenosphere conductivities reported in their Fig. 5 for $r=1$ (note that the labels for $r=0.6$ and $r=1$ are inverted on their figure since the slope for $r=1$ should be steepest).

The range of asthenosphere conductivities considered by Dai and Karato (2014a) merges distinct conductivities from two different settings. Evans et al. (2005) reported asthenosphere conductivities at 100-200 km beneath 1.3-4.5-My seafloor at southern East Pacific Rise (EPR) of $\sim 0.02 \mathrm{~S} / \mathrm{m}$ according to their isotropic model (see their Fig. 3a). This value can be reproduced by the model of Dai and Karato (2014a) and the other models at 100 wt.ppm or less (Fig. 1d). However, $\sim 10^{-2} \mathrm{~S} / \mathrm{m}$ is a value which falls in the mid-range of usual asthenosphere conductivities at these depths (up to $\sim 10^{-1} \mathrm{~S} / \mathrm{m}$; e.g. Lizarralde et al., 1995). Contrastingly, Naif et al. (2013) reported $0.17-0.25 \mathrm{~S} / \mathrm{m}$ around the lithosphere-asthenosphere boundary (45-70 km depths) beneath 23-My seafloor from EPR. These data are $\sim 1$ log unit higher in conductivity in a supposedly colder setting than Evans et al. (2005). The model of Dai and Karato (2014a) at 100 wt.ppm yields 1-2 log unit lower conductivities than Naif et al. (2013) (Fig. 1d). None of the hydrous olivine conductivity models at 100 wt.ppm can reproduce the data of Naif et al. (2013). These conductivities require unrealistically high temperatures or olivine water con- 
tents, both of them favoring melting. For instance, olivine with 100 wt.ppm can only reach $0.1 \mathrm{~S} / \mathrm{m}$ for temperatures $>1850^{\circ} \mathrm{C}$ according to the model of Dai and Karato (2014a). Water incorporation could be higher in olivines from old - and therefore cold - lithospheric mantle, but producing high conductivities requires concentrations far above relevant ranges to compensate the decrease in temperature. For instance, at $1100^{\circ} \mathrm{C}, 0.1 \mathrm{~S} / \mathrm{m}$ can only be reached with olivine having $>3500$ wt.ppm according to the model of Dai and Karato (2014a).

The model of Dai and Karato (2014a) is supposed to include a component for dry conduction according to their Eqs. (2) and (3), but they did not report parameters for it. Actually, they did not consider dry conduction since their model yields values down to $10^{-3} \mathrm{~S} / \mathrm{m}$ at $1423^{\circ} \mathrm{C}$ and at low water concentrations (see their Fig. 5), while conductivity in dry olivine is about $10^{-2} \mathrm{~S} / \mathrm{m}$ at $1400{ }^{\circ} \mathrm{C}$ (Fig. 1d; e.g. Gardés et al., 2014). Dry conduction mechanisms cannot be neglected as they may influence and even dominate hydrous olivine conductivity at asthenosphere-relevant temperatures and water concentrations.

The conductivity anisotropy of dry olivine is much lower than measured by Dai and Karato (2014a) in their hydrous olivines. Therefore, the conversion of their measurements at 1020 wt.ppm to lower concentrations should lower anisotropy, but this was not considered in the calculations reported in their Fig. 2. Indeed, anisotropy is drastically reduced when the dry conductivities of the model of Gardés et al. (2014) are added to the model of Dai and Karato (2014a) (Fig. 1e). At 100 wt.ppm, the anisotropy factor of hydrous olivine $\left(\sigma_{\max } / \sigma_{\min }\right)$ is $\sim 10$ over $1100-1600^{\circ} \mathrm{C}$ (Fig. 1e), which is much lower than the factors $\sim 30-50$ required to produce anisotropy factors of $\sim 2-3$ in a deformed mantle aggregate as considered by Dai and Karato (2014a).

The model of Dai and Karato (2014a), together with the other models, shows that hydrous olivine conductivity with mantlerelevant water concentration is compatible with usual upper mantle conductivities but is incompatible with the highest conductivities and is unlikely to produce significant conductivity anisotropy in deformed mantle. The highest conductivities of the upper mantle must therefore result from another process than olivine hydration, which is likely to be partial melting (e.g. Sifré et al., 2014).

\section{Acknowledgements}

This work, part of the ElectroLith project, benefited from funding by the European Research Council (ERC project \#279790) and the French agency for research (ANR project \#2010 BLAN 62101 ).

\section{Appendix A. Supplementary material}

Supplementary material related to this article can be found online at http://dx.doi.org/10.1016/j.epsl.2015.06.041.

\section{References}

Ardia, P., Hirschmann, M.M., Withers, A.C., Tenner, T.J., 2012. $\mathrm{H}_{2} \mathrm{O}$ storage capacity of olivine at 5-8 GPa and consequences for dehydration partial melting of the upper mantle. Earth Planet. Sci. Lett. 345-348, 104-116.

Dai, L., Karato, S., 2014a. High and highly anisotropic electrical conductivity of the asthenosphere due to hydrogen diffusion in olivine. Earth Planet. Sci. Lett. 408, 79-86.

Dai, L., Karato, S., 2014b. The effect of pressure on the electrical conductivity of olivine under the hydrogen-rich conditions. Phys. Earth Planet. Inter. 232, 51-56.

Dai, L., Karato, S., 2014c. Influence of oxygen fugacity on the electrical conductivity of olivine: implications for the mechanism of conduction. Phys. Earth Planet. Inter. 232, 57-60.

Demouchy, S., Mackwell, S.J., 2006. Mechanisms of hydrogen incorporation and diffusion in iron-bearing olivine. Phys. Chem. Miner. 33, 347-355.

DuFrane, W.L., Tyburczy, J.A., 2012. Deuterium-hydrogen exchange in olivine: implications for point defects and electrical conductivity. Geochem. Geophys. Geosyst. 13, Q03004.

Evans, R.L., Hirth, G., Baba, K., Forsyth, D.W., Chave, A., Makie, R., 2005. Geophysical evidence from the MELT area for compositional control on oceanic plates. Nature 437, 249-252.

Gardés, E., Gaillard, F., Tarits, P., 2014. Toward a unified hydrous olivine electrical conductivity law. Geochem. Geophys. Geosyst. 15. http://dx.doi.org/10.1002/ 2014GC005496.

Jones, A.G., Fullea, J., Evans, R.L., Muller, M.R., 2012. Water in cratonic lithosphere: calibrating laboratory determined models of electrical conductivity of mantle minerals using geophysical and petrological observations. Geochem. Geophys. Geosyst. 13, Q06010.

Kohlstedt, D.L., Mackwell, S.J., 1998. Diffusion of hydrogen and intrinsic point defects in olivine. Z. Phys. Chem. 207, 147-162.

Lizarralde, D., Chave, A., Hirth, G., Schultz, A., 1995. Northeastern Pacific mantle conductivity profile from long-period magnetotelluric sounding using Hawaiito-California submarine cable data. J. Geophys. Res. 100 (B9), 17837-17854.

Naif, S., Key, K., Constable, S., Evans, R.L., 2013. Melt-rich channel observed at the lithosphere-asthenosphere boundary. Nature 495, 356-359.

Paterson, M.S., 1982. The determination of hydroxyl by infrared absorption in quartz, silicate glasses and similar materials. Bull. Minéral. 105, 20-29.

Poe, B.T., Romano, C., Nestola, F., Smyth, J.R., 2010. Electrical conductivity anisotropy of dry and hydrous olivine at 8 GPa. Phys. Earth Planet. Inter. 181, 103-111.

Sifré, D., Gardés, E., Massuyeau, M., Hashim, L., Hier-Majumder, S., Gaillard, F., 2014. Electrical conductivity during incipient melting in the oceanic low-velocity zone. Nature 509, 81-85.

Wang, D., Mookherjee, M., Xu, Y., Karato, S., 2006. The effect of water on the electrical conductivity of olivine. Nature 443, 977-980.

Withers, A.C., Bureau, H., Raepsaet, C., Hirschmann, M.M., 2012. Calibration of infrared spectroscopy by elastic recoil detection analysis of $\mathrm{H}$ in synthetic olivine. Chem. Geol. 334, 92-98.

Yoshino, T., Matsuzaki, T., Shatskiy, A., Katsura, T., 2009. The effect of water on the electrical conductivity of olivine aggregates and its implications for the electrical structure of the upper mantle. Earth Planet. Sci. Lett. 288, 291-300. 